\title{
Ultrathin, Responsive Polymer Click Capsules
}

Georgina K. Such, Elvira Tjipto, Almar Postma, Angus P. R. Johnston, and Frank Caruso*

Centre for Nanoscience and Nanotechnology, Department of Chemical and Biomolecular Engineering,

The University of Melbourne, Victoria 3010, Australia

*Corresponding author: F. Caruso (E-mail: fcaruso@unimelb.edu.au)

\section{Supporting Information}
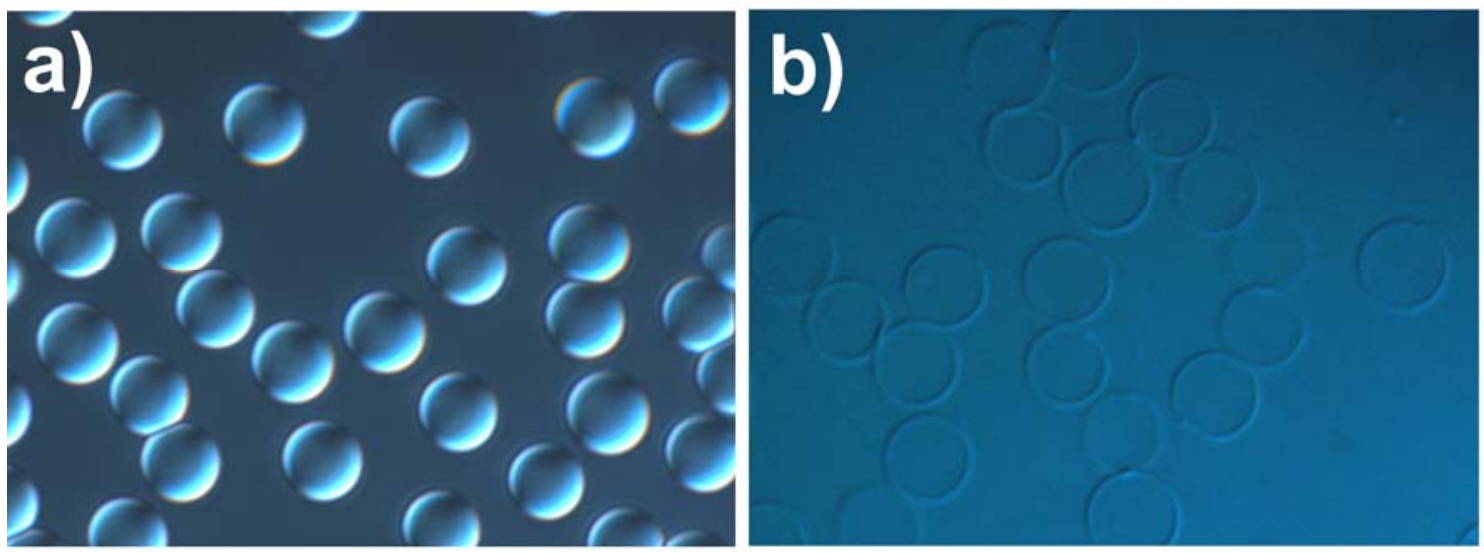

Figure S1. Nomarski (polarized) microscopy image of approximately $5 \mu \mathrm{m}$ (PAAAz/PAA-Alk) 6 (a) core-shell particles and (b) capsules.

Materials. High-purity (Milli-Q) water with a resistivity greater than $18 \mathrm{M} \Omega \mathrm{cm}$ was obtained from an in-line Millipore RiOs/Origin water purification system. Acrylic acid was purified by vacuum distillation and propargyl acrylate was purified by filtration through neutral alumina (70-230 mesh) immediately prior to use. Silica particles (diameter $\sim 5 \mu \mathrm{m}$ ) were obtained from Microparticles $\mathrm{GmbH}$ 
(Germany). All other chemicals were purchased from Sigma-Aldrich and used without further purification.

Polymer synthesis. (PAA-Az). Poly(acrylic acid) with azide functionality (PAA-Az) was synthesized by the following procedure. The initial reactants were mixed at an approximate 255:45:1 molar ratio of acrylic acid $\left(89.9 \times 10^{-2} \mathrm{~g}, 0.012 \mathrm{~mol}\right), 3$-chloropropyl acrylate $\left(31.7 \times 10^{-2} \mathrm{~g}, 0.0021 \mathrm{~mol}\right)$, RAFT agent (butyl phthalimidomethyl trithiocarbonate) $\left(15.3 \times 10^{-3} \mathrm{~g}, 0.00047 \mathrm{~mol}\right)$, and $5 \mathrm{~mL}$ dioxane. The synthesis of the 3-chloropropyl acrylate and RAFT agent has been described previously. ${ }^{1} 10 \mathrm{wt} \%$ azobisisobutyronitrile $\left(4.0 \times 10^{-1} \mathrm{mg}, 0.0024 \mathrm{mmol}\right)$ relative to the RAFT agent was also added. The solution was purged by bubbling with nitrogen for $45 \mathrm{~min}$ and then polymerized at $60{ }^{\circ} \mathrm{C}$ in a constant temperature oil bath $(14 \mathrm{~h})$. The product was dialyzed for $12 \mathrm{~h}$ to remove excess monomer. The polymer was then stirred for $24 \mathrm{~h}$ with sodium azide at $80{ }^{\circ} \mathrm{C}$. The final product was then dialyzed again for $24 \mathrm{~h}$ and freeze dried. ${ }^{1} \mathrm{H}$ NMR $\left(\mathrm{D}_{2} \mathrm{O}\right): 1.00-2.49 \mathrm{CH}_{2}$ and $\mathrm{CH}$ (polymer), pendant $\mathrm{CH}_{2} \mathrm{CH}_{2} \mathrm{CH}_{2}$ (polymer), 3.21-3.35 pendant $\mathrm{CH}_{2} \mathrm{~N}_{3}$ (polymer), 3.81-4.19 pendant $\mathrm{OCH}_{2}$ (polymer). The yellowish polymer obtained had a molecular weight of $135400\left(M_{\mathrm{n}}\right)$ with a polydispersity of 1.40 . The molecular weight was determined using PEG standards.

(PAA-Alk). Poly(acrylic acid) with alkyne functionality (PAA-Alk) was synthesized according to the following procedure. The initial reactants were mixed at an approximate 540:60:1 molar ratio of acrylic acid $\left(90.6 \times 10^{-2} \mathrm{~g}, 0.013 \mathrm{~mol}\right)$, propargyl acrylate $\left(18.1 \times 10^{-2} \mathrm{~g}, 0.0016 \mathrm{~mol}\right)$, RAFT agent (butyl phthalimidomethyl trithiocarbonate) $\left(7.6 \times 10^{-4} \mathrm{~g}, 0.00023 \mathrm{~mol}\right)$, and $4 \mathrm{~mL}$ dioxane. $10 \mathrm{wt} \%$ azobisisobutyronitrile $\left(2.0 \times 10^{-1} \mathrm{mg}, 0.0012 \mathrm{mmol}\right)$ relative to the RAFT agent was also added. The solution was purged by bubbling with nitrogen for $45 \mathrm{~min}$ and then polymerized at $60{ }^{\circ} \mathrm{C}$ in a constant temperature oil bath $(11 \mathrm{~h})$. The product was dialyzed for $24 \mathrm{~h}$ to remove excess monomer. ${ }^{1} \mathrm{H}$ NMR ( $\left.\mathrm{D}_{2} \mathrm{O}\right)$ ppm: 1.00-1.92 $\mathrm{CH}_{2}$ (polymer), 2.04-2.58 $\mathrm{CH}$ (polymer), 2.70-2.83 triple bond $\mathrm{CH}$ (polymer), the final polymer peak is combined with the solvent peak at 4.47-4.84 $\mathrm{OCH}_{2}$ (polymer). There was also a distinctive peak at $7.71 \mathrm{ppm}$ due to the phthalimdo protons on the RAFT agent. The yellowish 
polymer obtained had a molecular weight of $53000\left(M_{\mathrm{n}}\right)$ with a polydispersity of 1.9 . The molecular weight was analyzed using poly(styrene) standards. The larger polydispersity is ascribed to branching of the alkyne functional monomer, which produced a shoulder on the polymer distribution.

Polymer Labeling (PAA-Alk). PAA-Alk (40 mg) was added to a round bottom flask with copper sulfate $(5.6 \mathrm{mg})$ and sodium ascorbate $(12.8 \mathrm{mg})$ in $20 \mathrm{~mL}$ of water. A stock solution of azide-functionalized rhodamine dye (tetramethylrhodamine 5-carbonyl azide) was made up of $0.1 \mathrm{mg}$ of material dissolved in $1 \mathrm{~mL}$ dimethyl sulfoxide (DMSO). An aliquot of $0.1 \mathrm{~mL}$ of the dye solution was then added to the round bottom flask and stirred for $16 \mathrm{~h}$. The pink solution obtained was dialyzed for several days and then freeze-dried.

Multilayer Coating of Particles. Approximately $200 \mu \mathrm{L}$ of $5 \mathrm{wt} \%$ silica particles and $1.5 \mathrm{~mL}$ of water were added to a $2 \mathrm{~mL}$ centrifuge tube. The particles were first washed 3 times with water. The tube was agitated with a vortex mixer and then centrifuged at $1000 \mathrm{~g}$ for $1 \mathrm{~min}$. This resulted in a pellet forming at the bottom of the tube. Approximately $1.5 \mathrm{~mL}$ of the supernatant was removed and replaced with water. This was repeated twice prior to polyelectrolyte coating. After the last wash, approximately 1.5 $\mathrm{mL}$ of poly(ethyleneimine) $(\mathrm{PEI})$ solution $\left(1 \mathrm{mg} \mathrm{mL}^{-1}, 0.5 \mathrm{M} \mathrm{NaCl}\right)$ was added to establish a PEI layer on the particles. This dispersion was allowed to incubate for $15 \mathrm{~min}$, followed by 3 washing steps with Milli-Q water.

The following stock solutions were made: (a) PAA-Az $\left(0.83 \mathrm{mg} \mathrm{mL}^{-1}\right)$, (b) PAA-Alk $\left(0.83 \mathrm{mg} \mathrm{mL}^{-1}\right)$, (c) copper sulfate $\left(1.8 \mathrm{mg} \mathrm{mL}^{-1}\right)$ and $(\mathrm{d})$ sodium ascorbate $\left(4.4 \mathrm{mg} \mathrm{mL}^{-1}\right)$. The $\mathrm{pH}$ of each solution was adjusted to 3.5 using $0.1 \mathrm{M} \mathrm{HCl}$. The final PAA solutions for adsorption were made up in a constant volume ratio of $3(\mathrm{a}$ or $\mathrm{b}): 1(\mathrm{c}): 1(\mathrm{~d})$. To prevent oxidation of the copper, new copper stock solutions were prepared after deposition of each PAA-Az/PAA-Alk bilayer. 
After pre-coating with PEI, $1.5 \mathrm{~mL}$ of PAA-Az solution (containing copper and ascorbate) were added and allowed to incubate for $15 \mathrm{~min}$. After adsorption, the particles were washed 3 times with water (centrifugation speed of $100 \mathrm{~g}$ for $2 \mathrm{~min}$ to prevent particle aggregation). This was followed by adsorption of PAA-Alk, followed by the same washing steps with water. The process was repeated until the desired number of layers was deposited.

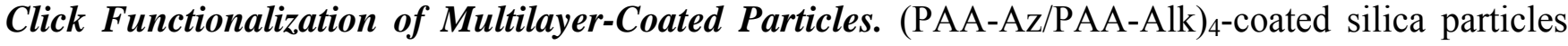
were coated with azide-functionalized rhodamine dye ( $\mathrm{Rh}-\mathrm{Az}$, the same dye used to functionalize PAAAlk). $0.5 \mu \mathrm{L}$ of $0.1 \mathrm{mg} \mathrm{mL} \mathrm{m}^{-1}$ of $\mathrm{Rh}-\mathrm{Az}$ was diluted in $1.5 \mathrm{~mL}$ of Milli-Q water. $0.6 \mathrm{~mL}$ of this solution was mixed with $0.2 \mathrm{~mL}$ of copper sulfate $\left(1.8 \mathrm{mg} \mathrm{mL}^{-1}\right)$ and $0.2 \mathrm{~mL}\left(4.4 \mathrm{mg} \mathrm{mL}^{-1}\right)$ of sodium ascorbate solutions. This mixture is then added to the (PAA-Az/PAA-Alk) $)_{4}$-coated silica particles and allowed to incubate for $30 \mathrm{~min}$. Then the particles were washed with $\mathrm{pH} 3.5$ water three times and 50/50 v/v DMSO/water 5 times to remove any unbound dye. The particle suspension was then dialyzed exhaustively against DMSO/water solution and washed another 10 times with DMSO/water solution. As a control, rhodamine dye that has not been click functionalized was used in place of Rh-Az. In the adsorption solution, $\mathrm{pH}$ 3.5-water was used instead of the copper sulfate and sodium ascorbate solutions. All other procedures were the same as above.

Preparation of Polymer Click Capsules. To form the click capsules, the silica core was dissolved by mixing $1 \mu \mathrm{L}$ of the polymer-coated particle suspension with $1 \mu \mathrm{L}$ of ammonium fluoride $(8 \mathrm{M})$ buffered HF $(2 \mathrm{M})$ at $\mathrm{pH} 5$ and the capsules were visualized in situ. (Caution! HF is highly toxic and great care must be taken when handling). Dissolution of the silica core occurred after less than 1 min. The particles were imaged on an Olympus IX71 fluorescence microscope.

Click Capsule Swelling/Shrinkage Experiments. $\mathrm{pH}$-induced swelling and shrinkage of the capsules was performed by alternately adding $1 \mu \mathrm{L}$ of $\mathrm{HCl}$ at $\mathrm{pH} 2$ and $1 \mu \mathrm{L}$ of $10 \mathrm{mM}$ sodium carbonate 
$\left(\mathrm{NaHCO}_{3} / \mathrm{Na}_{2} \mathrm{CO}_{3}\right)$ buffer solution at $\mathrm{pH} 10$ directly to the click capsule solution on the microscope slide. The shrinkage or swelling of the capsules occurred within less than 1 min of adding the acidic or basic solution. The size of the capsules quoted is the average of $\sim 10$ capsules.

Characterization Methods. Flow Cytometry. Flow cytometry was performed on a Becton Dickinson FACS Calibur flow cytometer. $5 \mu \mathrm{L}$ of the particle suspension was diluted in $250 \mu \mathrm{L}$ of $0.1 \mathrm{M} \mathrm{HCl}$ solution. Measurements were acquired by triggering on the forward scatter detection (EO detector) with a threshold of 400. Rhodamine fluorescence was monitored on the FL2 (570-610 nm) parameter with a PMT voltage of 600 V. Flow cytometry data analysis was performed with Summit v. 3.1 software (Cytomation Inc., Colorado, USA). The mean fluorescence intensity was obtained from the fluorescence intensity histograms.

DIC and Fluorescence Microscopy. An inverted Olympus IX71 microscope equipped with a DIC slider (U-DICT, Olympus) with a 40x objective lens (Olympus UPLFL20 /0.5 N.A., W.D. 1.6) was used to view the core-shell and hollow particles. A CCD camera (Cool SNAP $f x$, Photometrics, Tucson, AZ) was mounted on the left hand port of the microscope. Transmission and DIC images were illuminated with a tungsten lamp, and the fluorescence images were illuminated with a $\mathrm{Hg}$ arc lap, using a UF1032 filter cube.

Atomic Force Microscopy. AFM images were acquired of air-dried capsules on silicon wafers with a MFP-3D Asylum Research instrument. $5 \mu \mathrm{L}$ of capsule suspension was allowed to dry overnight on a clean piece of silicon wafer. Typical scans were conducted in AC mode with ultrasharp SiN gold coated cantilevers (NT-MDT) over $20 \mu \mathrm{m}^{2}$.

Transmission Electron Microscopy: Air-dried hollow capsules were characterized with a Philips CM120 BioTWIN TEM operated at $120 \mathrm{kV}$.

Gel Permeation Chromatography. (SEC) 
(PAA-Az) was analysed on a Shimadzu modular LC system comprising a DGU 12A solvent degasser, an LC-10AT pump, an SIL-10AD auto injector, an SIL-10A controller, an SPD-10AVP UV-Vis detector, an RID-10A refractive index detector, a Polymer Lab aquagel-OH 50 x $7.5 \mathrm{~mm}$ guard column and three $300 \times 7.5 \mathrm{~mm}$ aquagel-OH columns $(30,40,50)$ with a $8 \mu \mathrm{m}$ particle size. The mobile phase/eluent used is made up of water (distilled $\mathrm{H}_{2} \mathrm{O}+0.02 \% \mathrm{NaN}_{3}$ ). The system was calibrated with poly(ethylene glycol) standards $(4,600 \sim 400,000)$.

(PAA-Alk) was analysed on a Shimadzu modular system, comprising an autoinjector, a Polymer Laboratories $5.0 \mathrm{~m}$ bead-size $(50 \times 7.5 \mathrm{~mm})$, followed by three linear PL columns $\left(10^{5}, 10^{4}\right.$ and $\left.10^{3} \AA\right)$ and a differential refractive index detector. The eluent was $\mathrm{N}, \mathrm{N}$-dimethyl-acetamide $(0.5 \% \mathrm{LiBr})$ at $40{ }^{\circ} \mathrm{C}$ with a flow rate of $1 \mathrm{ml} \cdot \mathrm{min}^{-1}$. The system was calibrated using narrow polystyrene standards ranging from 500 to $10^{6}$ g.mol-1.

(1) Postma, A.; Davis, T. P.; Evans, R. A.; Li, G.; Moad, G.; O'Shea, M. S. Macromolecules 2006, 39, 5293-5306. 